\title{
Double Cropping in Vitis vinifera L. Pinot Noir: Myth or Reality?
}

\author{
Stefano Poni ${ }^{1, *}$, Matteo Gatti ${ }^{1}{ }^{(0)}$, Sergio Tombesi ${ }^{1}$, Cecilia Squeri ${ }^{1}$, Paolo Sabbatini ${ }^{2}{ }^{\circledR}$, \\ Nieves Lavado Rodas ${ }^{3}$ (D) and Tommaso Frioni ${ }^{1}$ (D) \\ 1 Department of Sustainable Crop Production, Università Cattolica del Sacro Cuore, Via Emilia Parmense, 84, \\ 29122 Piacenza, Italy; matteo.gatti@unicatt.it (M.G.); sergio.tombesi@unicatt.it (S.T.); \\ cecilia.squeri@unicatt.it (C.S.); tommaso.frioni@unicatt.it (T.F.) \\ 2 Department of Horticulture, Michigan State University, East Lansing, MI 48824, USA; sabbatin@msu.edu \\ 3 Centre for Scientific and Technological Research of Extremadura CICYTEX (Junta de Extremadura), \\ Finca La Orden, Ctra. A-V, km 372, 06187 Guadajira, Badajoz, Spain; nieves.lavado@juntaex.es \\ * Correspondence: stefano.poni@unicatt.it
}

Received: 23 April 2020; Accepted: 2 June 2020; Published: 4 June 2020

check for updates

\begin{abstract}
A novel bud-forcing technique aimed at obtaining two crops (primary and forced) within the same season was tested on potted Pinot noir grapevines. Removing young, vegetative organs from primary shoots trimmed to six nodes in early summer allows dormant buds to break para-dormancy, leading to a delayed, second crop. Meanwhile, the primary crop is left untouched. In our study, bud-forcing was applied at three different timings (full flowering, fruit-set, groat-sized berries) and compared with an unforced control (UC). Vegetative growth, yield components, shoot and vine balance as leaf area-to-yield ratios, leaf gas exchange, and grape composition were determined. Regardless of the timing of application, forcing was effective at unlocking either apical or sub-apical dormant buds on the trimmed shoot, whereas the more basal nodes stayed dormant. The additional crop present on forced shoots was $40 \%-50 \%$ of primary crop, which equated to approximately $1 \mathrm{~kg} / \mathrm{vine}$ for all treatments. Fruitfulness on newly formed forced shoots varied from 0.8 to 1.1 clusters/shoot. Primary clusters in vines subjected to forced treatments reached target maturity with a delay of 7-12 days compared to UC, whereas forced-crop, picked at the latest available date (October 7) showed higher total soluble solids, anthocyanins and phenolics than the primary crop while retaining higher acidity. This ripening behavior was reflected in the higher A rates measured in late season on the basal leaves of forced shoots versus those of primary shoots. Forcing did not compromise fruitfulness of the basal primary nodes, which set at about 1.2 inflorescence primordia/shoot. This is the first report supporting the feasibility of double cropping in Vitis vinifera L. in warm viticulture regions.
\end{abstract}

Keywords: dormant bud; yield; grape composition; vine balance; gas exchange; phenology

\section{Introduction}

A consequence of rising day and night-time temperatures in warm grape-growing regions is the acceleration and uncoupling of ripening dynamics that separately lead to the accumulation of hexoses and phenolic in fruit [1]. An additional negative consequence of these conditions is the hastening of ripening-time among cultivars previously having a larger separation. This creates a challenge for harvest-time decision making, as well as for transportation and winery logistics [2].

Recent literature reviews have provided a detailed description of techniques utilized to delay ripening dynamics $[1,3,4]$. These practices differ in application simplicity, duration of effects, economic suitability, and potential impacts on fruitfulness. Among them, winter pruning performed at the bud swollen stage can stop and/or delay bud development by a few days, which can also avoid a late 
spring frost event [5,6]. More recently, a number of publications [7-12] encompassing a wide range of genotypes, environments, and cultural practices have shown that retarding spur pruning up to the stage when, in the apical part of the still unpruned canes, shoots have already reached the $2-4$ unfolded leaf stage of development, would delay bud burst from the basal nodes by over a month and postpone harvest up to 3 weeks.

Most promisingly, an understudied approach is double pruning/cropping, which was first tested by Dry in 1987 on Shiraz [13]. This technique consisted of trimming canes in the summer to six nodes, and concurrently removing all laterals and clusters to force the dormant $n+2$ compound bud to push before entering endo-dormancy. This delay to the crop cycle positioned fruit ripening in a cooler period of the season and grape composition was greatly enhanced. The same technique was more recently applied by Gu et al. [14], who, in the hot climate of Fresno (California), compared four dates of dormant bud forcing on Cabernet Sauvignon. Ripening was delayed by up to two months vs. The unforced control (for the hedging performed between 21 and 42 days after anthesis), and interestingly, berry flavonoids increased linearly until harvest in forced vines, while flavonoids in the control had peaked and began to decrease [14]. In 2019, De Toda et al. [15] tested different dates of forcing in Tempranillo and Maturana tinta cultivars, which consisted of trimming the primary shoot between $2^{\text {nd }}$ and $3^{\text {rd }}$ internode. A consistent delay in ripening was observed (up to two months vs. The unforced control) among all forced treatments; however, this came at the expense of a decrease in yield per vine and bud fruitfulness. Similar results were obtained by Martinez-Moreno et al. [16] and by Lavado et al. [17] in cv. Tempranillo.

Despite the effectiveness of bud forcing at maintaining fruit quality in some studies, the practice has a low likelihood of being adopted by the industry due to three main limitations: i) the drastic trimming of shoots and removal of all leaves on the primary shoot cause a strong source limitation that can severely impair current and next season's yield; ii) the removal of all primary clusters and main and lateral leaves (needed to unlock the dormant compound buds) can be very time consuming; iii) most importantly, convincing a grape grower to drop the entire primary crop, trusting that a second crop will originate from the unlocked dormant compound buds is a very difficult task.

The objective of this work carried out on fruiting, potted Pinot noir grapevines was to provide proof of concept for a totally new forcing technique aimed at preserving also fruit quality of the primary crop. We hypothesized that severe early spring trimming of main shoots coupled with removal of developing laterals will promote growth of the compound bud. The originated forced shoots will warrant a second delayed crop, enhancing yield and shifting maturity into a much cooler period. Moreover, we predicted that maintaining the basal leaves on primary shoots will ensure fruitfulness at the basal nodes, therefore preserving next-year cropping potential.

\section{Materials and Methods}

\subsection{Plant Material and Experimental Layout}

The experiment was carried out in 2019 at the Department of Sustainable Crop Production (DIPROVES) of the Università Cattolica del Sacro Cuore in Piacenza $\left(45^{\circ} 02^{\prime} \mathrm{N}, 9^{\circ} 43^{\prime} \mathrm{E}, 54 \mathrm{~m}\right.$ asl), Italy using 16 three year old grapevines cv. Pinot Noir (clone VCR18 grafted on Kober 5BB) grown outside in $35 \mathrm{~L}$ pots filled with a mixture of sand, peat and loamy soil $(30 \%, 20 \%$ and $50 \%$ by volume, respectively). Vines were spur-pruned to leave $4-5$ two-count-node spurs per vine. After bud burst (BBCH 15 according to Lorenz et al. [18]), vines were thinned to one shoot per node while cropping level was standardized removing any distal inflorescence on the primary shoots. Any shoots coming from base buds were also removed. From the initial group, each vine was randomly assigned to one of the following treatments (4 vines per treatment): Unforced control (UC), meaning that primary shoots were left to grow and trimmed to retain 13-14 main leaves only once they outgrew the top foliage wire; forcing one (F1) where all main shoots were trimmed above node 6 on DOY (Day Of the Year) 154, corresponding to the phenological stage $\mathrm{BBCH} 65$ (full flowering with $50 \%$ of flower caps 
fallen according to Lorenz et al. [18]); concurrently, any already developed lateral shoot was removed from the retained nodes. Forcing two (F2) and forcing three (F3) differed from F1 only in terms of date of application that was DOY 162 (corresponding to BBCH 69, end of flowering) and DOY 175 (corresponding to BBCH 73, groat (pea)-sized berries) for F2 and F3, respectively. In F1, F2 and F3 vines, developing lateral shoots were weekly removed until the end of June. After DOY 182, no lateral shoots developed anymore.

In all $\mathrm{F}$ treatments, normal crop from trimmed primary shoots was maintained. No trimming was performed on the shoots growing from the forced compound buds even if they outgrew the top wire, and clusters developed on the forced shoots were not thinned and/or standardized. In all treatments, the date of budburst was recorded as well as the veraison stage at $5 \%$ berry color change.

Pots were painted white to minimize possible overheating of the root system. Number and intensity of daily irrigation events was calibrated to assure pot water capacity not to decrease below 90\%; pest management was primarily focused against downy and powdery mildews and followed sustainable local practices. Figure 1 shows a detail of the dormant bud exiting dormancy (a), of the surface cut performed on the primary shoot with an already developed forced shoot (b) and of primary and forced crop bore on the same vine (c).
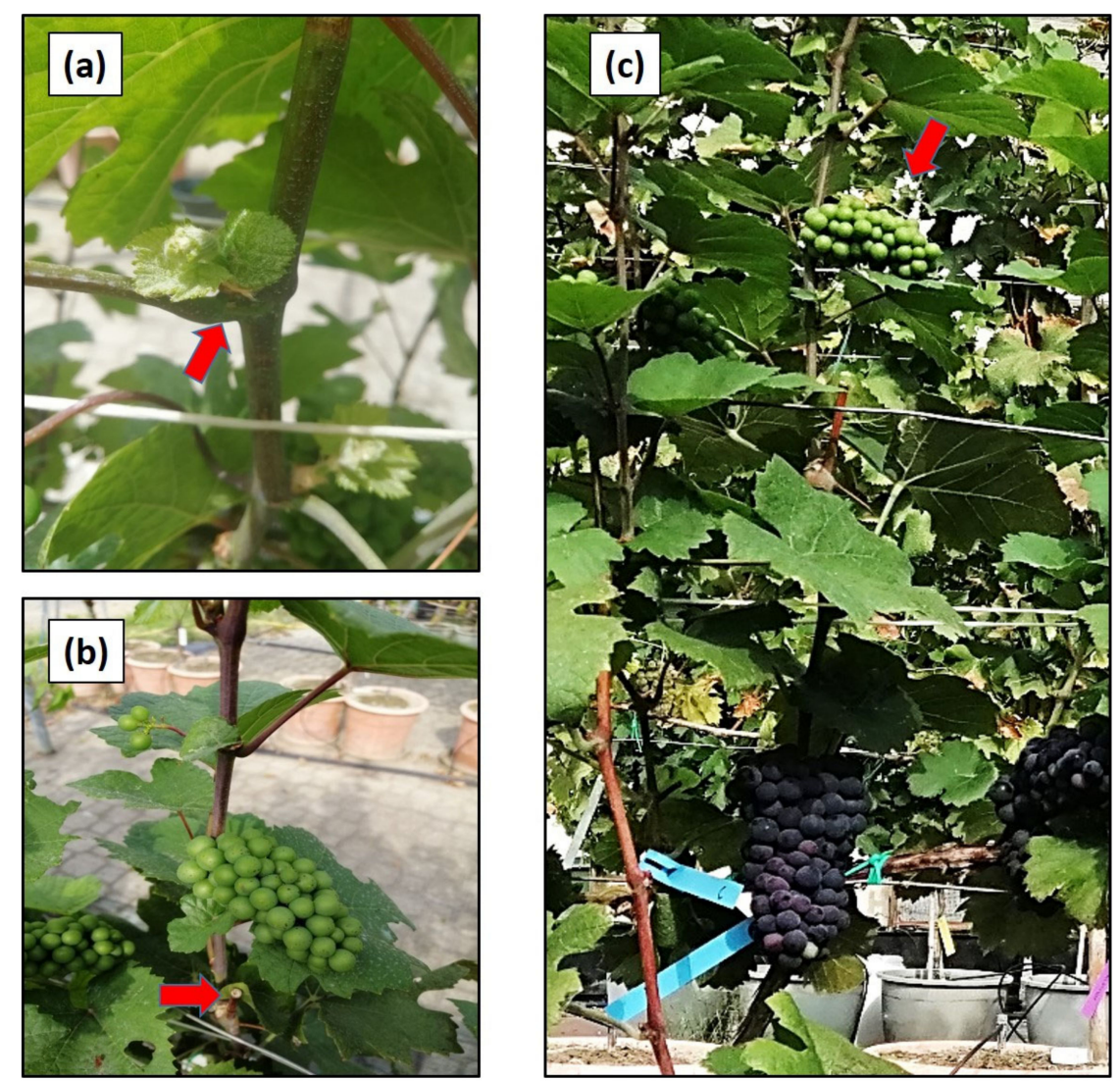

Figure 1. Different stages of the forcing process. Arrow indicates: In panel (a), a dormant bud pushing from a primary node; in panel (b), the trimming cut on the primary shoot and, above, a well-developed cluster on the forced shoot originated by the apical node of the trimmed primary shoot; in panel (c), the forced cluster bore on the same vine where the primary cluster is approaching ripening.

\subsection{Vine Measurements}

At the time of each forcing, removed main and lateral leaves were separated and their fresh weight recorded. Then, samples were brought to the lab and leaf area was measured with a desk leaf area meter (LI-3000A leaf-area meter, LI-COR Biosciences, Lincoln, NE, USA). Three primary shoots per vine originating from the distal node of three different spurs were tagged to perform specific 
measurements. Total primary and forced shoot number per vine were recorded along with their fertility given as number of clusters per main or forced shoot. On each trimmed shoot, the node position originating a forced shoot from the compound or dormant bud was registered, together with the shoot diameter measured at the internode located between nodes 3-4. After the harvest of forced crop, in all treatments, primary tagged shoots and forced shoots were individually defoliated recording the number of leaves and their leaf area was separately measured. In UC, the contribution of laterals developed prior or after trimming was also added. Main single leaf areas for primary, forced and lateral shoots were calculated. Immediately after leaf fall, the number of nodes on primary and forced shoots as well as on UC lateral shoots was counted. The final leaf area for each type of shoot was estimated based on node counts and leaf blade areas. Total vine leaf area was then calculated as a sum of the three components.

\subsection{Primary and Forced Crop Components}

At the stage of separate flowers, all inflorescences on tagged and forced shoots were photographed against a dark background. In extra-vines of the same cultivar, pictures of 20 inflorescences were taken with the same methods before being sampled and brought to the lab, where the number of total flowers per inflorescence was destructively counted. A linear regression $\left(y=2.03 \times, R^{2}=0.86\right)$ between the actual flower number $(\mathrm{y})$ and the number of flowers counted on the photo $(\mathrm{x})$ was calculated and used to estimate total flower number on the photographed inflorescences of tagged shoot and forced shoots of experimental vines. Fruit set was then calculated as the percentage of flowers developing into normal size berries at harvest.

Harvest of primary crop produced on each treatment was performed at different dates, based on fruit ripening progression. A sample of berries from the primary crop of each treatment was periodically taken to assess soluble solids concentration (TSS), $\mathrm{pH}$ and titratable acidity (TA). The primary crop was harvested when fruit of the specific treatment achieved a TA of $\sim 8 \mathrm{~g} / \mathrm{L}$, identified as the optimal threshold for Pinot Noir premium sparkling wines. The weight of primary crop was measured with a field portable scale and the number of clusters recorded. Mean cluster weight was then calculated accordingly. The clusters from tagged primary shoots (three per vine) were sampled and used to determine rachis length, number of berries per cluster, berry weight and cluster compactness, calculated as unit $(\mathrm{g})$ of fruit mass per unit $(\mathrm{cm})$ of rachis.

To explore maximum ripening delay potential of the forcing technique, harvest date was the same (DOY 280, 7 October) for all the forced shoots. This was the latest date available before berries started to dehydrate and/or rot. Yield components were analyzed as previously described for the primary crop. Vine balance indexed as total leaf area-to-yield ratio was calculated for primary and forced shoots, as well as on a whole vine basis.

\subsection{Fruit Composition}

At harvest for both primary and secondary crop, a sample of 100 berries per vine and crop type was crushed to obtain a must. The TSS concentration was measured using a temperature-compensating RX 5000 refractometer (Atago, Bellevue, WA, USA) and must pH analyzed with a digital PHM82 pH meter (Radiometer Analytical, Villeurbanne, France). For the determination of titrable acidity (TA), $10 \mathrm{~mL}$ of juice solution was titrated against a standardized $0.1 \mathrm{~N} \mathrm{NaOH}$ solution to a $\mathrm{pH} 8.2$ end-point and expressed as $\mathrm{g} / \mathrm{L}$ of tartaric acid equivalents using a Crison Compact Titrator (Crison, Barcelona, Spain). Tartaric acid and malic acid were quantified via HPLC after filtering juice through a $0.22 \mu \mathrm{m}$ polypropylene syringe into auto-sampler vials. For this analysis, an Allure Organic Acid Column, $300 \times 4.6 \mathrm{~mm}, 5 \mu \mathrm{m}$ (Restek, Bellefonte, PA, USA) was used. Separation was performed in isocratic conditions using water, $\mathrm{pH}$ adjusted at 2.5 with ortho-phosporic acid. The column temperature was maintained at $30 \pm 0.1{ }^{\circ} \mathrm{C}$ and $15 \mu \mathrm{L}$ of sample was injected. The elution was monitored at 200-700 $\mathrm{nm}$ and detection by UV-vis absorption with DAD at $210 \mathrm{~nm}$. Organic acids were identified 
using authentic standards and quantification was based on peak areas and performed by external calibration with standards.

Fifty berries per vine for either primary and forced crop were used to determine total anthocyanins and phenolics. Berries were homogenized at $3584 \times g$ with an Ultra-Turrax T25 (Rose Scientific Ltd., Edmonton, Canada) homogenizer for $1 \mathrm{~min}$, then $2 \mathrm{~g}$ of the homogenate was transferred to a pre-tared centrifuge tube, enriched with $10 \mathrm{~mL}$ aqueous ethanol (50\%, pH 5.0), capped and mixed periodically for $1 \mathrm{~h}$ before centrifugation at $959 \times \mathrm{G}$ for $5 \mathrm{~min}$. A portion of the extract $(0.5 \mathrm{~mL})$ was added to $10 \mathrm{~mL} 1 \mathrm{M}$ $\mathrm{HCl}$, mixed and let stand for $3 \mathrm{~h}$; absorbance was then measured at $520 \mathrm{~nm}$ and $280 \mathrm{~nm}$ on a JascoV-530 UV spectrophotometer (Jasco Analytical Instruments, Easton, MD, USA). Total anthocyanins and phenolics were expressed as mg per $g$ of fresh berry mass [19].

\subsection{Gas Exchange Measurements}

Leaf gas-exchange measurements were periodically taken during the season on primary and forced shoots of all the experimental vines. In more details, readings regarded the $3^{\text {rd }}$ leaf of main shoots of all treatments and, on the forced shoots, the $3^{\text {rd }}$ leaf of F1, F2 and F3 (only after their full expansion) was also used. Measurements were performed on DOYs 152, 161 and 174 (i.e., the days before F1, F2 and F3 application), DOY 206 (veraison of UC) and DOY 252. Readings were taken between 11:30 and 12:30, under saturating light conditions (PAR $>1400 \mathrm{mmol} \mathrm{m}^{-2} \mathrm{~s}^{-1}$ ), on one leaf for each shoot type per vine, using a portable, gas exchange open system, LCi infrared gas analyzer (ADC Bio Scientific Ltd., Hertz, UK). The system was equipped with a broad leaf chamber with a $6.25 \mathrm{~cm}^{2}$ window and all readings were taken at ambient relative humidity with an airflow adjusted to $350 \mathrm{~mL} \mathrm{~min}^{-1}$. The assimilation rate (leaf A), and stomatal conductance (leaf $\mathrm{g}_{\mathrm{s}}$ ) were calculated from inlet and outlet $\mathrm{CO}_{2}$ and $\mathrm{H}_{2} \mathrm{O}$ concentrations.

\subsection{Assessment of Bud Fruitfulness}

The potential yield of the grapevine for the next season or potential fruitfulness is indicated by the number and size of the inflorescence primordia at the onset of dormancy [20,21]. At the end of the season, three canes per treatment were collected and transported to the lab. Subsequently, all dormant buds were dissected under a stereo microscope (40× magnification) as described by Sanchez and Dokoozlian [22]. The number of inflorescence primordia in each primary bud was recorded and potential fruitfulness of buds according to their position on the cane was expressed as number of inflorescence primordia per primary bud.

\subsection{Data Analysis}

Data were subjected to a one-way ANOVA performed with XLSTAT statistical package (Addinsoft, New York, NY, USA) according to the completely randomized design that was used. In case of significant $\mathrm{F}$ test, means separation among UC vs. all forcing treatment was performed with a Student-Neumann-Keuls test, whereas, within each forcing treatment, separation between primary and forced shoots parameters was performed with a $t$-test. Repeated measures of the same parameters (A and $\mathrm{g}_{s}$ rates) taken at different dates along the season were analyzed with the Repeated Measure analysis of variance routine embedded in the XLSTAT software package. The least squared (LS) mean method at $p=<0.05$ was used for multiple comparisons within dates.

\section{Results}

\subsection{Seasonal Weather Pattern and Phenology}

During the experiment, growing degree days (GDD) calculated according to Winkler Index (1 April-30 September) were 2077 and total rainfall over the same time period was $375 \mathrm{~mm}$ (Figure 2). The season reported a wet and cool spring; in May, mean daily T was $15.6^{\circ} \mathrm{C}$, cumulated GDD were 175 and total rainfall reached $175 \mathrm{~mm}$. Conversely, June was dry and hot with almost no rain, having a 
GDD of 468 and a mean daily T of $25.6{ }^{\circ} \mathrm{C}$. Thermal trends of July and August were like June, although in July $54 \mathrm{~mm}$ of precipitations occurred. Finally, September saw high precipitation (64 $\mathrm{mm})$ and was cool with a mean daily $\mathrm{T}$ of $20.8^{\circ} \mathrm{C}$.

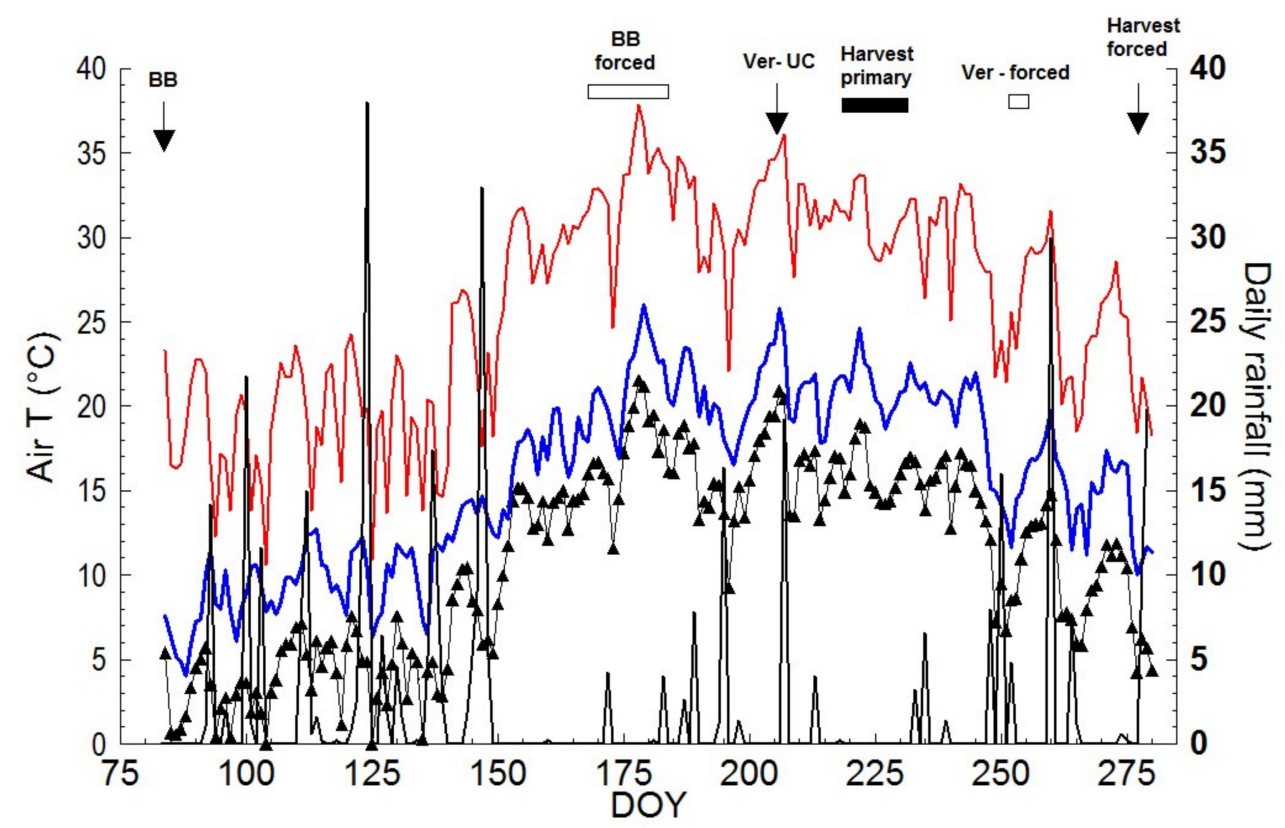

Figure 2. Seasonal daily trends of minimum temperature (black line and triangle), mean temperature (blue line), maximum temperature (red line) and rainfall (peaks). Top annotations indicate the dates of main phenological stages and harvest for unforced control (UC) and forced vines. BB = Bud-break, Ver $=$ Veraison, $\mathrm{DOY}=$ Day of the Year, $\mathrm{T}=$ Temperature .

Initial budburst occurred in all treatments on 25 March (DOY 84), whereas budburst of the different forced treatments spanned from 17 June to 2 July (DOY 168-183). The primary crop of unforced vines reached veraison on 25 July, while the primary crop of forced treatments reached the same stage 7-13 days later and this phenological delay was maintained until harvest. Forced clusters had a greatly delayed veraison (up to 50-53 days) when compared to the primary unforced clusters.

UC vines required 1391 GDD and 135 days from budburst to targeted technological maturity (Table 1). Being that the GDD/day was relatively constant, a proportionally higher number of days and GDD were needed for primary clusters in forced treatment vines to reach a similar ripening target. Forced clusters were able to complete the transition from budburst to harvest in fewer days (97-112) likely due to higher available GDD/day. The number of days from veraison to harvest for primary clusters in all treatments was very similar as a likely consequence of a very constant GDD/day value (about 16). Conversely, forced clusters underwent a veraison-to-harvest transition during a cooler period (9.5 to 11 GDD/day), requiring an increased number of days. 
Table 1. Number of days, daily $T_{\text {mean, }}$ base 10 growing degree days (GGD) and GDD/day calculated from bud break to harvest and from veraison to harvest for the primary crop of unforced control (UC) and forced $(\mathrm{F})$ treatments and for the forced crop of each forcing treatment.

\begin{tabular}{|c|c|c|c|c|c|c|c|c|}
\hline \multirow{3}{*}{ Treatment } & \multicolumn{8}{|c|}{ Bud Break-Harvest } \\
\hline & \multicolumn{4}{|c|}{ Primary Crop } & \multicolumn{4}{|c|}{ Forced Crop } \\
\hline & Days & $\mathrm{T}_{\text {Mean }}\left({ }^{\circ} \mathrm{C}\right)$ & GDD $\left({ }^{\circ} \mathrm{C}\right)$ & DD/day $\left({ }^{\circ} \mathrm{C}\right)$ & Days & $\mathrm{T}_{\text {MEAN }}\left({ }^{\circ} \mathrm{C}\right)$ & GDD $\left({ }^{\circ} \mathrm{C}\right)$ & DD/day $\left({ }^{\circ} \mathrm{C}\right)$ \\
\hline UC & 135 & 20.2 & 1391 & 10.3 & - & - & - & - \\
\hline $\mathrm{F} 1$ & 147 & 20.7 & 1584 & 10.8 & 112 & 24.2 & 1595 & 14.2 \\
\hline F2 & 142 & 20.5 & 1507 & 10.6 & 108 & 24.2 & 1531 & 14.2 \\
\hline \multirow[t]{4}{*}{ F3 } & 148 & 20.7 & 1601 & 10.8 & 97 & 23.8 & 1331 & 13.7 \\
\hline & \multicolumn{8}{|c|}{ Veraison-Harvest } \\
\hline & \multicolumn{4}{|c|}{ Primary crop } & \multicolumn{4}{|c|}{ Forced crop } \\
\hline & Days & $\mathbf{T}_{\text {mean }}\left({ }^{\circ} \mathrm{C}\right)$ & GDD $\left({ }^{\circ} \mathrm{C}\right)$ & DD/day $\left({ }^{\circ} \mathrm{C}\right)$ & Days & $\mathrm{T}_{\text {mean }}\left({ }^{\circ} \mathrm{C}\right)$ & GDD $\left({ }^{\circ} \mathrm{C}\right)$ & $\mathrm{DD} /$ day $\left({ }^{\circ} \mathrm{C}\right)$ \\
\hline UC & 13 & 26.3 & 208 & 16 & - & - & - & - \\
\hline $\mathrm{F} 1$ & 12 & 26 & 192 & 16 & 28 & 19.5 & 267 & 9.5 \\
\hline F2 & 12 & 26.1 & 195 & 16.2 & 25 & 19.5 & 285 & 11.4 \\
\hline F3 & 12 & 26.1 & 193 & 16.1 & 25 & 19.5 & 285 & 11.4 \\
\hline
\end{tabular}

\subsection{Vegetative Growth, Yield and Vine Balance}

As expected, the amount of primary and lateral leaves removed by the trimming application in the three forcing treatments was higher the later the forcing was applied (Table 2). The highest removed main and lateral leaf areas $\left(0.89 \mathrm{~m}^{2}\right.$ and $0.12 \mathrm{~m}^{2}$, respectively) were registered in $\mathrm{F} 3$, and such values were three- and four-fold higher, respectively, than the area removed at F1 (Table 2).

Table 2. Number and amounts (surface and fresh mass) of primary and lateral leaves removed in each forcing treatment. LA = leaf area.

\begin{tabular}{ccccccc}
\hline Treatments & $\begin{array}{c}\text { Main } \\
\text { Leaves }\end{array}$ & $\begin{array}{c}\text { Lateral } \\
\text { Leaves }\end{array}$ & Main LA & Lateral LA & $\begin{array}{c}\text { Main Leaf } \\
\text { Mass }\end{array}$ & $\begin{array}{c}\text { Lateral Leaf } \\
\text { Mass }\end{array}$ \\
\hline F1 & $(n)$ & $(n)$ & $\left(\mathrm{m}^{2}\right)$ & $\left(\mathrm{m}^{2}\right)$ & $(\mathrm{g})$ & $(\mathrm{g})$ \\
$\mathrm{F} 2$ & $63 \mathrm{c}$ & $19 \mathrm{~b}$ & $0.30 \mathrm{c}$ & $0.03 \mathrm{~b}$ & $70 \mathrm{~b}$ & $3 \mathrm{c}$ \\
F3 & $118 \mathrm{~b}$ & $45 \mathrm{a}$ & $0.72 \mathrm{~b}$ & $0.09 \mathrm{a}$ & $315 \mathrm{a}$ & $24 \mathrm{~b}$ \\
F test & $155 \mathrm{a}$ & $56 \mathrm{a}$ & $0.89 \mathrm{a}$ & $0.12 \mathrm{a}$ & $360 \mathrm{a}$ & $41 \mathrm{a}$ \\
$* * *$ & $* * *$ & $* * *$ & $* * *$ & $* *$ \\
\hline
\end{tabular}

Mean separation (small case letters) within each column was performed by the Student-Newman-Keuls test. Means followed by the same letter do not differ (ns) or differ at $p=0.05\left(^{*}\right)$ or $P=0.001\left(^{* * *}\right)$.

For any forcing date, aptitude to release bud para-dormancy was exponentially related to the basal diameter of the trimmed primary shoot; diameters 6-7 $\mathrm{mm}$ achieved higher rates of bud para-dormancy breaking, hence, higher number of inflorescences carried by the newly forced shoots (Figure 3a-c). Dormancy breaking did not involve all of the buds retained on the primary shoot after its trimming. Independently by the timing of forcing application, only the two apical nodes and, occasionally, the third node below the trimming cut produced forced shoots, whereas basal nodes (including base bud until the third count node) remained dormant (Figure 3d-f). The average number of forced shoots per each primary shoot was highest on F2 (0.75) (Table 3).

Trimming and progressive laterals removal severely curtailed primary vine leaf area at harvest (about $0.40 \mathrm{~m}^{2}$ in F treatments) when compared to $1.12 \mathrm{~m}^{2}$ recorded in UC. Total vine LA was very similar between UC and F2 whereas F1 and F3 showed lower total vine LA at harvest (Table 3).

Before standardization to one cluster/shoot, fruitfulness of primary shoots was high in all treatments (about 1.6 inflorescences/shoot), whereas fertility on the forced shoots varied from 0.83 in F1 up to 1.05 in F2 (Table 3). Regardless of treatment, no differences were found in flower number per cluster of primary shoots. Instead, in forced shoots, F1 reported a very high flower number per inflorescence (265) that diminished in F2 and F3 to similar values to UC. Dissection of compound buds 
removed from primary canes of each treatment after leaf fall showed a good and uniform potential fruitfulness for the next year's cropping in all treatments, the inflorescence primordia (IP) being about 1.2 per primary bud over the three basal count nodes (Table 3).

The later the forcing, the more reduced was the rachis length in forced clusters (Table 4). While berry size was very uniform across primary shoots regardless the treatment (about $1 \mathrm{~g}$ of fresh mass), F2 clusters had smaller berries and this, in turn, reduced their compactness (Table 4). F2 and F3 shoots showed also fewer berries per cluster when compared to F1 shoots. Fruit set of clusters on primary and forced shoot was not changed by any of the treatments, whereas forced clusters/vine were fewer than primary clusters/vine with the largest difference in F1 as relation to UC (4 vs. 10). Forced F2 and F3 shoots also had smaller clusters as compared to primary clusters and F1 clusters. Yield per vine represented by primary clusters was very similar across treatments (about $1 \mathrm{~kg}$ ), whereas yield formed on forced shoots varied from $0.4 \mathrm{~kg}$ in F2 to 0.56 in F1 (Table 4).

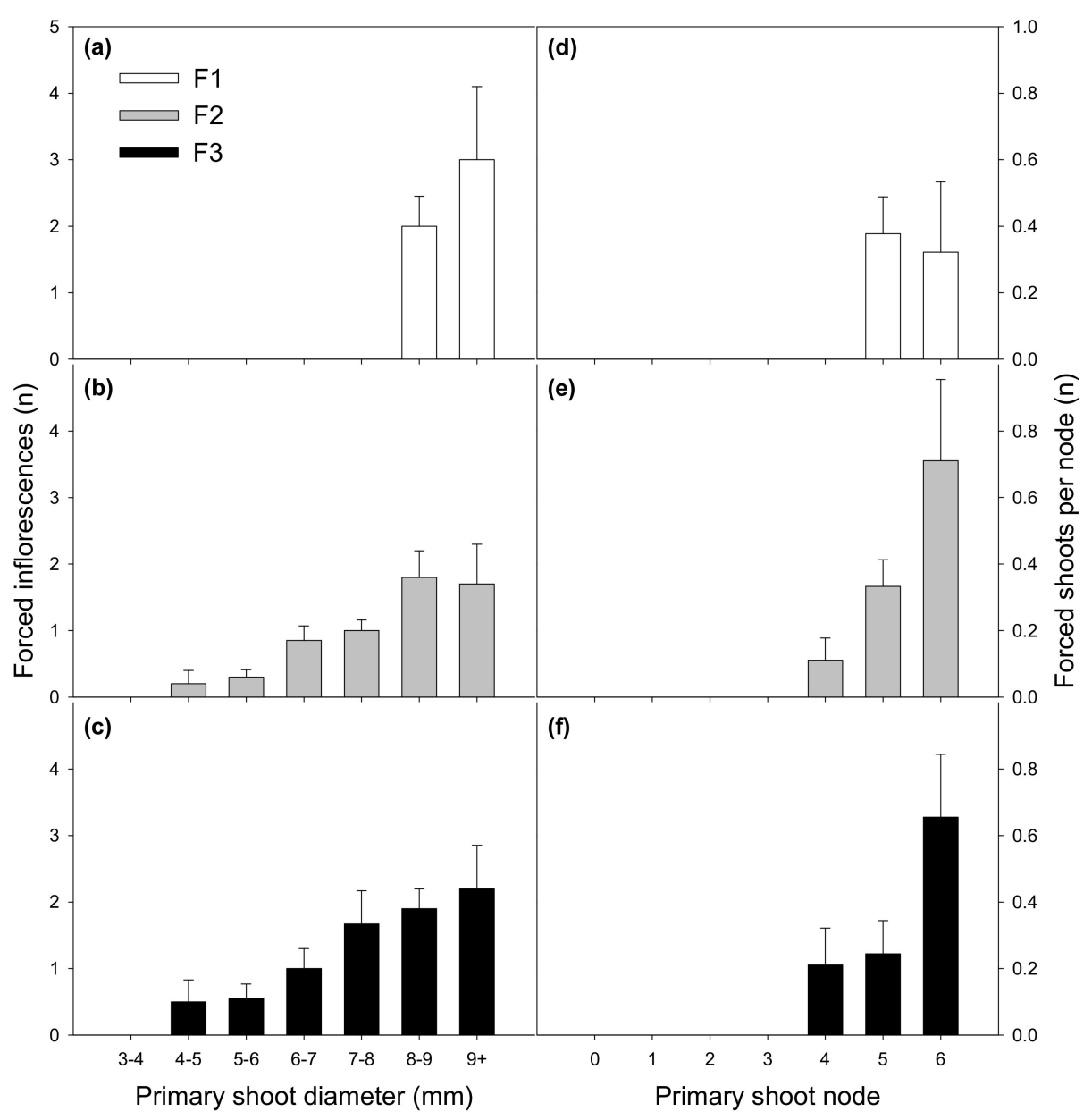

Figure 3. Average number of inflorescences carried on forced shoots produced per each primary shoot as a function of shoot diameter $(\mathbf{a}, \mathbf{b}$ and $\mathbf{c})$ and average number of forced shoots produced as a function of the node position on the trimmed primary shoot $(\mathbf{d}$, e and $\mathbf{f})$. UC $=$ Unforced Control, F1 = Forcing applied at full flowering, F2 = Forcing applied at the end of flowering, F3 = Forcing applied at groat-sized berries. 
Table 3. Vegetative growth and fruitfulness recorded on primary and forced shoots. Last column reports inflorescence primordia (IP)/primary bud derived from bud dissection observation and data are pooled for the first three count nodes of primary canes. UC $=$ unforced control; LA $=$ leaf area.

\begin{tabular}{|c|c|c|c|c|c|c|c|c|c|c|c|c|c|c|c|}
\hline \multirow{2}{*}{ Treatments } & \multirow{2}{*}{$\begin{array}{c}\text { Forced Shoots } \\
\text { per Primary } \\
\text { Shoot }(n)\end{array}$} & \multicolumn{3}{|c|}{ Inflorescences per Shoot $(n)$} & \multicolumn{3}{|c|}{ Flowers/Cluster ( $n$ ) } & \multicolumn{3}{|c|}{ Shoot LA $\left(\mathrm{m}^{2}\right)$} & \multicolumn{3}{|c|}{ Vine LA $\left(\mathrm{m}^{2}\right)$} & \multirow{2}{*}{$\begin{array}{c}\text { Total Vine } \\
\text { LA }\left(\mathrm{m}^{2}\right)\end{array}$} & \multirow{2}{*}{$\begin{array}{l}\text { IP/Primary } \\
\quad \text { Bud }(n)\end{array}$} \\
\hline & & Primary & Forced & $t$-Test & Primary & Forced & $t$-Test & Primary & Forced & $t$-Test & Primary & Forced & $t$-Test & & \\
\hline $\mathrm{UC}$ & - & 1.61 & - & - & 139 & - & - & $0.200 \mathrm{a}$ & - & - & $1.12 \mathrm{a}$ & $0 \mathrm{~b}$ & - & $1.12 \mathrm{a}$ & 1.21 \\
\hline F1 & $0.49 \mathrm{~b}$ & 1.76 & $0.83 \mathrm{~b}$ & $* * *$ & 186 & $265 \mathrm{a}$ & $* * *$ & $0.041 \mathrm{~b}$ & 0.101 & $* * *$ & $0.39 \mathrm{~b}$ & $0.46 \mathrm{~b}$ & $*$ & $0.86 \mathrm{~b}$ & 1.16 \\
\hline F2 & $0.75 \mathrm{a}$ & 1.73 & $1.05 \mathrm{a}$ & $* * *$ & 145 & $128 \mathrm{~b}$ & ns & $0.040 \mathrm{~b}$ & 0.113 & $* * *$ & $0.42 \mathrm{~b}$ & $0.68 \mathrm{a}$ & $* * *$ & $1.10 \mathrm{a}$ & 1.35 \\
\hline F3 & $0.69 \mathrm{a}$ & 1.63 & $0.89 \mathrm{ab}$ & $* * *$ & 151 & $162 \mathrm{~b}$ & ns & $0.042 \mathrm{~b}$ & 0.104 & $* * *$ & $0.41 \mathrm{~b}$ & $0.38 \mathrm{~b}$ & ns & $0.78 \mathrm{~b}$ & 1.28 \\
\hline F test & ** & ns & * & & ns & $* * *$ & & $* * *$ & ns & & $* * *$ & $* * *$ & & $* * *$ & ns \\
\hline
\end{tabular}

Mean separation (small case letters) within each column was performed by the Student-Newman-Keuls test. Within each row and parameter, primary vs. forced comparison was scored by $t$-test. Means followed by the same letter do not differ (ns) or differ at $p=0.05\left(^{*}\right)$ or $P=0.001(* * *)$.

Table 4. Yield and cluster morphology components recorded on primary and forced shoots. UC $=$ unforced control.

\begin{tabular}{|c|c|c|c|c|c|c|c|c|c|c|c|c|c|}
\hline \multirow[b]{3}{*}{ Treatments } & \multicolumn{3}{|c|}{ Rachis Length } & \multicolumn{3}{|c|}{ Cluster Compactness } & \multicolumn{4}{|c|}{ Berries per Cluster } & \multicolumn{3}{|c|}{ Fruit Set } \\
\hline & \multicolumn{3}{|c|}{$(\mathrm{cm})$} & \multicolumn{3}{|c|}{$(\mathrm{g} / \mathrm{cm})$} & \multicolumn{4}{|c|}{$(n)$} & \multicolumn{3}{|c|}{$(\%)$} \\
\hline & Primary & Forced & $t$-test & Primary & Forced & $t$-test & Prim & & Forced & $t$-test & Primary & Forced & $t$-test \\
\hline $\mathrm{UC}$ & 8.27 & - & - & 14.24 & - & - & 10 & & - & - & 46 & - & - \\
\hline $\mathrm{F} 1$ & 10.29 & $7.92 \mathrm{a}$ & ns & 16.20 & $11.15 \mathrm{a}$ & * & 12 & & $145 \mathrm{a}$ & ns & 53 & 52 & ns \\
\hline F2 & 8.61 & $6.37 \mathrm{~b}$ & ns & 13.77 & $8.59 \mathrm{~b}$ & $* *$ & 97 & & $73 \mathrm{~b}$ & $* *$ & 45 & 56 & ns \\
\hline F3 & 10.31 & $5.12 \mathrm{~b}$ & $* *$ & 12.86 & $11.22 \mathrm{a}$ & ns & 12 & & $78 \mathrm{~b}$ & $* * *$ & 53 & 49 & ns \\
\hline \multirow[t]{2}{*}{ F test } & ns & $* *$ & & ns & ${ }^{*}$ & & $\mathrm{~ns}$ & & $* * *$ & & ns & ns & \\
\hline & \multicolumn{3}{|c|}{ Berry Weight (g) } & \multicolumn{3}{|c|}{ Cluster Weight (g) } & \multicolumn{3}{|c|}{ Yield/Vine (kg) } & \multicolumn{2}{|c|}{ Clusters/Vine $(n)$} & \multicolumn{2}{|c|}{$\begin{array}{c}\text { Forced/Primary Yield } \\
\text { Ratio }\end{array}$} \\
\hline Treatments & Primary & Forced & $t$-test & Primary & Forced & $t$-test & Primary & Forced & $t$-test & Primary & Forced & $t$-test & \\
\hline UC & 1.09 & - & & 114 & - & - & 1.02 & $0.00 \mathrm{~b}$ & $* * *$ & 9 & - & - & $0.00 \mathrm{~b}$ \\
\hline $\mathrm{F} 1$ & 0.95 & $0.96 \mathrm{a}$ & ns & 121 & $140 \mathrm{a}$ & ns & 1.15 & $0.56 \mathrm{a}$ & $* * *$ & 10 & $4 \mathrm{~b}$ & $* * *$ & $0.49 \mathrm{a}$ \\
\hline F2 & 1.02 & $0.78 \mathrm{~b}$ & $*$ & 99 & $57 \mathrm{~b}$ & $* *$ & 1.00 & $0.40 \mathrm{a}$ & $* * *$ & 10 & $7 \mathrm{a}$ & * & $0.40 \mathrm{a}$ \\
\hline F3 & 0.99 & $0.94 \mathrm{a}$ & ns & 127 & $73 \mathrm{~b}$ & $* * *$ & 1.02 & $0.44 \mathrm{a}$ & $* * *$ & 8 & $6 a$ & $*$ & $0.43 \mathrm{a}$ \\
\hline $\mathrm{F}$ test & ns & $* *$ & & ns & $* * *$ & & ns & $* * *$ & & ns & $* *$ & & $* * *$ \\
\hline
\end{tabular}

Mean separation (small case letters) within each column was performed by the Student-Neumann-Keuls test. Within each row and parameter, primary vs. forced comparison was scored by $t$-test. Means followed by the same letter do not differ (ns) or differ at $p=0.05(*), P=0.01(* *)$ or $P=0.001(* *)$. 
The single shoot supply-demand balance given as leaf area-to-fruit ratios was largely insufficient in primary shoots of all forcing treatments $\left(0.3-0.4 \mathrm{~m}^{2} / \mathrm{kg}\right)$, whereas it increased in forced shoots. In particular, in $\mathrm{F} 2$, shoots reached a LA/Y ratio of $1.7 \mathrm{~m}^{2} / \mathrm{kg}$ (Table 5). When the same parameter was calculated as total vine leaf area to total yield contributed by primary shoots, ratios greatly improved and UC and F2 reached the same value $\left(1.1 \mathrm{~m}^{2} / \mathrm{kg}\right)$. The highest LA/Y ratios were achieved, though, when total leaf area per vine was referred to total yield carried by forced shoots. Total vine LA-to-total yield ratio was limited by any forcing treatments, albeit F2 performed better than F1 and F3.

Table 5. Shoot and vine balance given as leaf area (LA) to yield (Y) ratios for UC and forced treatments. $\mathrm{UC}=$ unforced control.

\begin{tabular}{|c|c|c|c|c|c|c|c|}
\hline \multirow{2}{*}{ Treatments } & \multicolumn{3}{|c|}{ Shoot LA/Y Ratio $\left(\mathrm{m}^{2} / \mathrm{Kg}\right)$} & \multicolumn{3}{|c|}{ Vine LA/Y Ratio $\left(\mathrm{m}^{2} / \mathrm{Kg}\right)$} & \multirow{2}{*}{$\begin{array}{c}\text { Total Vine LA/Y } \\
\text { Ratio }\left(\mathrm{m}^{2} / \mathrm{Kg}\right)\end{array}$} \\
\hline & Primary & Forced & $t$ Test & Primary & Forced & $t$ Test & \\
\hline $\mathrm{UC}$ & $1.10 \mathrm{a}$ & - & - & $1.10 \mathrm{a}$ & - & - & $1.10 \mathrm{a}$ \\
\hline $\mathrm{F} 1$ & $0.34 \mathrm{~b}$ & $0.82 \mathrm{~b}$ & $* *$ & $0.75 \mathrm{~b}$ & $1.54 \mathrm{~b}$ & $* * *$ & $0.50 \mathrm{c}$ \\
\hline F2 & $0.41 \mathrm{~b}$ & $1.70 \mathrm{a}$ & $* * *$ & $1.10 \mathrm{a}$ & $2.75 \mathrm{a}$ & $* * *$ & $0.79 \mathrm{~b}$ \\
\hline F3 & $0.40 \mathrm{~b}$ & $0.95 b$ & $* * *$ & $0.76 \mathrm{~b}$ & $1.77 \mathrm{~b}$ & $* * *$ & $0.53 c$ \\
\hline F test & $* * *$ & $* * *$ & & $* * *$ & $* * *$ & & $* * *$ \\
\hline
\end{tabular}

Mean separation (small case letters) within each column was performed by the Student-Neumann-Keuls test. Within each row and parameter, primary vs. forced comparison was scored by $t$-test. Means followed by the same letter do not differ (ns) or differ at $\left.P=0.01{ }^{* *}\right)$ or $\left.P=0.001{ }^{* * *}\right)$.

\subsection{Grape Composition}

Grape composition at harvest greatly differed between primary and forced shoots (Table 6). UC was harvested on August 7 (DOY 219) with an overall grape composition ideal for Pinot noir sparkling wine production. Primary clusters carried on each forcing treatment achieved similar grape composition at their respective harvest dates (7, 12, 13 d later for F2, F1 and F3, respectively), under one main exception given by F1. In particular, F1 had lower TSS, total anthocyanins and phenolics than UC, whereas tartrate and malate were higher.

Forced crop harvested in all treatments on October 7 (DOY 280) had a high TSS $\left(21.2^{\circ}\right.$ Brix in F3 to $23.2^{\circ}$ Brix in F2) and uniform, high TA (13-14 g/L) when compared to UC. Such high TA was exclusively due to the greatly increased malic acid $(5-6 \mathrm{~g} / \mathrm{L})$ as compared to malate concentration measured on clusters carried by primary shoots $(1.5-2.5 \mathrm{~g} / \mathrm{L})$. Within forced treatments, F2 and F3 had higher total anthocyanins than F1, whereas forced clusters had 2-3-fold higher pigmentation than corresponding primary clusters. A similar behavior was found for total phenolics, albeit limited to F1 and F3 treatments. 
Table 6. Fruit technological and phenolic maturity parameters determined at harvest on clusters carried by primary and forced shoots. TSS = total soluble solids; $\mathrm{TA}=$ titratable acidity; $\mathrm{UC}=$ unforced controls

\begin{tabular}{|c|c|c|c|c|c|c|c|c|c|c|c|c|c|c|c|c|}
\hline \multirow[t]{2}{*}{ Treatments } & \multicolumn{3}{|c|}{$\begin{array}{l}\text { Harvest Dates } \\
\text { (DOY) }\end{array}$} & \multicolumn{3}{|c|}{$\begin{array}{c}\text { TSS } \\
\left({ }^{\circ} \text { Brix }\right)\end{array}$} & \multicolumn{4}{|c|}{$\mathrm{pH}$} & \multicolumn{3}{|c|}{$\begin{array}{c}\text { TA } \\
(\mathrm{g} / \mathrm{L})\end{array}$} & \multicolumn{3}{|c|}{ TSS/TA } \\
\hline & Primary & & Forced & Primary & Forced & $t$ - Test & Primar & & Forced & $t$ - Test & Primary & Forced & $t$ - Test & Primary & Forced & $t$-Test \\
\hline UC & 219 & & - & $18.9 \mathrm{a}$ & - & - & 3.15 & & - & - & 7.8 & - & - & $2.42 \mathrm{a}$ & - & - \\
\hline F1 & 231 & & 280 & $17.3 \mathrm{~b}$ & $22.2 \mathrm{ab}$ & $* * *$ & 3.11 & & 2.93 & $* * *$ & 8.5 & 14.2 & $* * *$ & $2.04 \mathrm{~b}$ & 1.67 & $* * *$ \\
\hline F2 & 226 & & 280 & $18.2 \mathrm{ab}$ & $23.2 \mathrm{a}$ & $* * *$ & 3.18 & & 2.91 & $* * *$ & 7.6 & 14.4 & $* * *$ & $2.39 \mathrm{a}$ & 1.62 & $* * *$ \\
\hline F3 & 232 & & 280 & $18.6 \mathrm{a}$ & $21.2 \mathrm{~b}$ & $* * *$ & 3.13 & & 2.91 & $* * *$ & 7.9 & 13.6 & $* * *$ & $2.35 \mathrm{a}$ & 1.60 & $* * *$ \\
\hline \multirow[t]{2}{*}{$F$ test } & - & & - & $* *$ & $*$ & & ns & & ns & & ns & ns & & $* * *$ & ns & \\
\hline & \multicolumn{3}{|c|}{$\begin{array}{l}\text { Malic Acid } \\
\text { (g/L) }\end{array}$} & \multicolumn{3}{|c|}{$\begin{array}{c}\text { Tartaric Acid } \\
(\mathrm{g} / \mathrm{L})\end{array}$} & \multicolumn{4}{|c|}{ Tartaric-to-malic ratio } & \multicolumn{3}{|c|}{$\begin{array}{c}\text { Anthocyanins } \\
(\mathrm{mg} / \mathrm{g})\end{array}$} & \multicolumn{3}{|c|}{$\begin{array}{c}\text { Phenolics } \\
\text { (mg/g) }\end{array}$} \\
\hline Treatments & Primary & Forced & $t$ - Test & Primary & Forced & $t$ - Test & Primary & Forced & & $t$-Test & Primary & Forced & $t$ - Test & Primary & Forced & $t$ - Test \\
\hline UC & $1.78 \mathrm{~b}$ & - & - & $7.41 \mathrm{c}$ & - & - & 4.16 & - & & - & $0.591 \mathrm{a}$ & - & - & $3.60 \mathrm{a}$ & - & - \\
\hline F1 & $2.44 \mathrm{a}$ & 5.27 & $* * *$ & $9.15 \mathrm{a}$ & 7.81 & $\mathrm{~ns}$ & 3.75 & 1.48 & & $* * *$ & $0.227 \mathrm{~b}$ & $0.705 \mathrm{~b}$ & $* * *$ & $2.92 \mathrm{~b}$ & $3.28 \mathrm{~b}$ & $* * *$ \\
\hline F2 & $2.23 \mathrm{a}$ & 5.33 & $* * *$ & $8.11 \mathrm{~b}$ & 8.25 & $\mathrm{~ns}$ & 3.64 & 1.55 & & $* * *$ & $0.472 \mathrm{ab}$ & $0.981 \mathrm{a}$ & $* * *$ & $3.30 \mathrm{ab}$ & $3.69 \mathrm{a}$ & $* *$ \\
\hline F3 & $2.12 \mathrm{ab}$ & 6.22 & $* * *$ & $9.41 \mathrm{a}$ & 6.23 & ns & 4.44 & 1.00 & & $* * *$ & $0.375 \mathrm{ab}$ & $0.895 \mathrm{a}$ & $* * *$ & $3.60 \mathrm{a}$ & $3.46 \mathrm{ab}$ & ns \\
\hline F test & $* * *$ & ns & & ** & ns & & ns & $\mathrm{ns}$ & & & * & $* *$ & & $* * *$ & * & \\
\hline
\end{tabular}

Mean separation (small case letters) within each column was performed by the Student-Neumann-Keuls test. Within each row and parameter, primary vs. forced comparison was scored by $t$-test. Means followed by the same letter do not differ (ns) or differ at $p=0.05\left(^{*}\right), P=0.01(* *)$ or $P=0.001\left(^{* * *}\right)$. 


\subsection{Leaf Gas Exchange}

Gas exchange (i.e., $\mathrm{A}$ and $\mathrm{g}_{\mathrm{s}}$ ) measurements were taken during the growing season on the third basal leaves of primary shoots for each treatment and covered about 100 days of leaf age span. They showed a typical aging pattern, with lowest rates reported on DOY 206 and 252 (Figure 4). Repeated measures analyses demonstrated that on DOY 162,175 and 206, $g_{s}$ rates measured on the $3^{\text {rd }}$ main leaf carried on the primary shoots of forced treatment were generally higher than those recorded on the UC vines; however, at such differences in $\mathrm{g}_{\mathrm{s}}$ they did not correspond to a significant difference in A rates. In contrast, large differences were shown when comparing $A$ and $g_{s}$ rates of $3^{\text {rd }}$ basal leaves inserted on primary or forced shoots; on DOY 206 (date of veraison for UC clusters), A and $\mathrm{g}_{\mathrm{s}}$ rates of UC leaves were $10.8 \mu \mathrm{mol} \mathrm{m}{ }^{-2} \mathrm{~s}^{-1}$ and $0.181 \mathrm{~mol} \mathrm{~m}^{-2} \mathrm{~s}^{-1}$, respectively, versus $15.0 \mu \mathrm{mol} \mathrm{m}^{-2} \mathrm{~s}^{-1}$ and $0.264 \mathrm{~mol} \mathrm{~m}^{-2} \mathrm{~s}^{-1}$ of forced shoots $3^{\text {rd }}$ node leaves (data pooled over F1, F2 and F3). Over the last sampling date (DOY 252, September 9), UC leaves had A and $g_{s}$ rates of $6.7 \mu \mathrm{mol} \mathrm{m}^{-2} \mathrm{~s}^{-1}$ and $0.120 \mathrm{~mol} \mathrm{~m}^{-2} \mathrm{~s}^{-1}$, respectively, whereas A and $\mathrm{g}_{\mathrm{s}}$ rates recorded on the forced shoots of pooled forcing treatments were set at $12.3 \mu \mathrm{mol} \mathrm{m}^{-2} \mathrm{~s}^{-1}$ and $0.183 \mathrm{~mol} \mathrm{~m}^{-2} \mathrm{~s}^{-1}$.

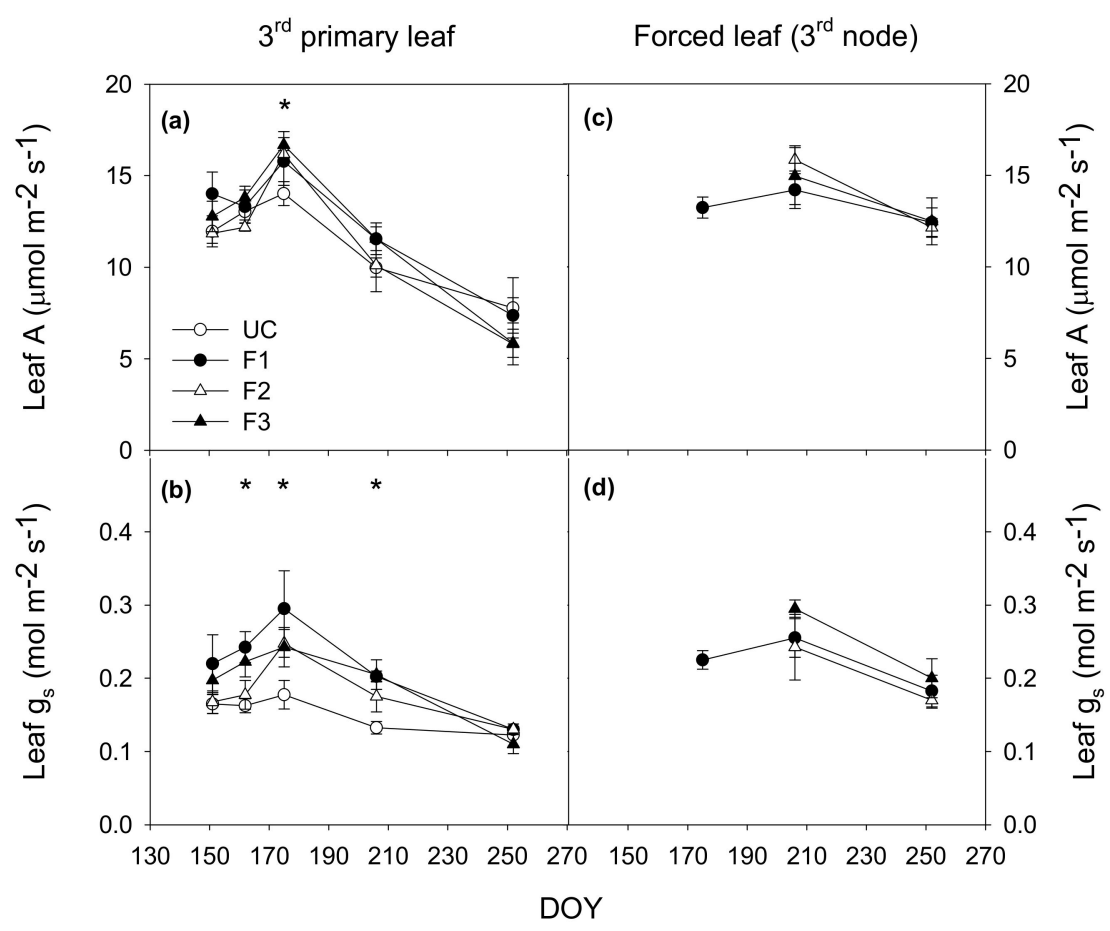

Figure 4. Evolution of leaf assimilation (Leaf A, panels a, c) and leaf stomatal conductance (Leaf $g_{s}$, panels $b, d$ ) measured on the $3^{\text {rd }}$ leaf of primary shoots (panels $\mathbf{a}, \mathbf{b}$ ) and on the 3rd expanded leaf of forced shoots (panels c, d). UC = Unforced Control, F1 = Forcing applied at full flowering, F2 = Forcing applied at the end of flowering, F3 = Forcing applied at groat sized berries.

\section{Discussion}

This work is, to our knowledge, the first attempt to obtain a second harvest from a Vitis vinifera wine grape cultivar grown in a temperate climate. Shoots were forced in early summer by breaking compound bud dormancy without compromising the standard primary crop and the possibility to have intact and fruitful wood for the next year's cropping. Our results confirm that such multiple goals can be achieved.

The first item that had to be resolved was to verify the degree of para-dormancy control exerted by the basal leaves of the growing shoot on the differentiating dormant buds. According to previous shoot and bud anatomy work, it is known that para-dormancy of a dormant bud during its first season of induction and differentiation can be released only if mature vegetative organs are left on the growing 
shoot [23-26]. In fact, regardless of the timing of forcing, shoot trimming above node 6 and the removal of any laterals has proved effective to break the dormancy of apical dormant buds. Concurrently, it has also been clarified that the presence, at the time of forcing, of green berries at varying stages of development on the primary clusters does not prevent dormant buds to exit para-dormancy. Then, at least three other major requirements have to be met to support the feasibility of the technique: i) the released dormant buds should preferably be those at the apical first or second node of each trimmed shoot to leave the first three basal dormant buds that will be retained after winter pruning undisturbed; ii) to provide suitable pruning wood for next year cropping these basal dormant buds are required to go through regular bud induction; iii) the unlocked dormant buds should be given enough time to undergo induction and differentiation of inflorescence primordia.

Data shown in Table 3 as the number of forced shoots per primary shoot ratio indicate that the forcing energy was quite mild, especially in F1, setting at 0.49 . Such a weak response can be explained by the lack of vigor. A basal diameter of 6-7 $\mathrm{mm}$ was required to push a forcing response (Figure 3). Although vines were spur-pruned-a pruning technique that usually improves shoot uniformity compared to long-cane pruning [27] —spurs left in the central part of the cordon tended to produce weaker shoots and some of them did not respond to forcing. It is our belief that being implemented on more vigorous, field grown spur-pruned plants might easily fix this potential drawback.

The suitable fruitfulness of the dormant buds located at the base of the trimmed shoot and to be used as next season fruiting spurs were also met, as their fertility ranged across 1.2 inflorescence primordia per shoot (Table 3), which is adequate for the adoption of short pruning. Interestingly, no differences in IP occurred between the undisturbed shoots of UC and the primary shoots of the forcing treatments, suggesting either that bud induction had already been completed by the time forcing treatments were implemented or, likely in F1, preservation of the mature leaves (nodes 1-6) was sufficient to support induction. It could also be argued that IF values (Table 2) were lower than current year shoot fruitfulness, setting at about 1.6-1.7 clusters/shoot. The weather pattern recorded in 2019 is a likely explanation for this difference; GGD and precipitation volume were abnormally low and high, respectively, during the month of May. Bud induction and initial differentiation typically take place during this time, so these negative conditions might have hindered the process [28].

The third basic requirement of having sufficient fruitfulness for each forced shoot was also satisfied, as all forcing treatments reached (F2) or approached (F1 and F3) the ideal values of one cluster per shoot. On a more practical basis, this means that any forcing carried out between DOY 154 (full flowering of UC) and DOY 175 (pea-size of UC) is suitable. The later the forcing was implemented, the higher the area of source leaves was removed from shoots (Table 2), and the higher the chance that the dormant bud induction process had already taken place. Moreover, similarly to IP observed in winter, forced shoots fruitfulness could have been negatively affected by the pre-flowering weather pattern. Theoretically, with more favorable temperatures in May, fruit could have set even closer to primary shoot fruitfulness levels.

An intriguing aspect of successfully implemented crop-forcing is the effects on yield components. Forcing provided $40 \%-50 \%$ additional yield ( $1 \mathrm{~kg} /$ vine) over UC vines, however, yield components varied substantially depending on the time of forcing. F1 forced clusters had a higher flower number than the other treatments that translated to a fruit set that was almost double that of F2 and F3 (Table 4). The forced dormant buds undergo an uninterrupted cycle of induction and differentiation of floral organs, whereas in a normal biannual bud cycle, flower number is also affected by environmental conditions and vegetative growth gradient along the productive unit (either spur or cane) during springtime of the second year [28]. The earliest forcing might have benefitted from either better environmental conditions upon dormant bud pushing and/or by the fact that main shoot trimming in F1 has removed a much lower LA than F2 and F3 (Table 2), thereby making the developing buds a stronger sink. Despite the high berry number per cluster, F1 clusters did not show higher compactness than F3 for instance, as the effect due to the increased berry number was counteracted by a longer rachis. 
Although the criteria for harvest were different for primary and forced clusters (primary clusters were harvested at a common TA, while forced clusters were harvested at the same date), the large differences observed in TSS, TA and total anthocyanins between the two cropping cycles is important for the potential implementation of this practice in temperate climates. The positive effects of crop-forcing on harvest grape composition in primary and forced clusters involve both the delay of key phenological stages and the dynamic changes in leaf function and vine balance. LA regrowth triggered by forcing allowed F2 to fully compensate LA, which was similar to UC harvest. Meanwhile, F1 and F3 had a lower final LA than UC. In F1, total LA was limited by a lower number of forced shoots; conversely, F3 regrowth upon forcing was insufficient to replenish previously removed LA. When also taking into account that $\mathrm{F}$ treatments assured additional yield, the final total LA/Y ratios for all $\mathrm{F}$ treatments were lower than the ratio calculated for UC, setting at $1.1 \mathrm{~m}^{2} / \mathrm{kg}$. In particular, LA/Y ratios calculated at harvest for $\mathrm{F} 1$ and $\mathrm{F} 3$, ranging near $0.5 \mathrm{~m}^{2} / \mathrm{kg}$, are much lower than the minimum threshold $\left(1 \mathrm{~m}^{2} / \mathrm{kg}\right)$ that, according to the literature, is supposed to be necessary to prevent limitations on sugar accumulation [29]. However, comparing such final LA/Y ratios with the overall grape composition recorded in either primary or forced clusters make very clear that, under these circumstances, they are not fully reliable.

At the date of UC harvest, the primary clusters bore on forced vines were still lagging behind and required an additional 7-12-days to ripen. On a practical basis, having to differentiate also the picking dates of the primary clusters is time consuming, especially when considering that a second harvest for the forced crop is also scheduled. However, the F2 treatment had only a 7-d delay and such a gap can be easily negotiated by adjusting a common harvest dates with UC. F1 and F3 had a longer delay that matches quite well with the more limiting LA/Y at harvest. Even in this case, though, room of improvement can be easily found by rendering the response to forcing stronger (i.e., higher vigor of the trimmed shoots or environment allowing an even longer growing season). This is similar to the work of Poni and Giachino [30], who imposed shoot trimming treatments at six nodes with or without lateral removal at fruit set using potted Cabernet Sauvignon vines. They found that when laterals were removed in addition to trimming, ripening was largely incomplete due to a limiting LA/Y ratio; whereas when laterals where untouched, TSS and color at harvest were only slightly limited as compared to the untrimmed control.

Traits of grape composition recorded in the forced clusters yielded a different and very interesting response. All forced treatments showed a great potential for continuing to accumulate sugar and anthocyanins until late in the season; higher values than those for regular crop picking were reached. Similar performances were also shown in forced crop of Cabernet Sauvignon [14], and Tempranillo [16]. As shown in Table 5, LA/Y ratio of forced treatments, regardless of the unit of expression (single shoot or whole vine) were much higher than the corresponding ratios in primary shoots, which likely provided more potential for sugar and color accumulation. In addition to having a larger canopy in relation to crop level, the "quality" of foliage was also higher. Forced clusters were accompanied by a younger, and therefore, more functional canopy as compared to primary clusters during the transition from veraison to harvest. This effect is clearly manifested by post-veraison A rates measured on either primary and forced leaves at the same node (third from the base of the stem). Forced shoots had 4-6 $\mu \mathrm{mol} \mathrm{m}{ }^{-2} \mathrm{~s}^{-1}$ higher A rates than those measured in UC. A final reason explaining the better color in forced clusters is the climactic conditions during which ripening took place. Postponing the ripening process to a much cooler period of the season (Table 1) is beneficial for either anthocyanins synthesis and preservation [1].

An intriguing outcome in the grape composition of forced clusters was that, despite sugar and color accumulation being at or above optima, TA was still too high, oscillating around 13-14 g/L. This difference was reflected in the malic acid content, which was 5-6 g/L at harvest in forced clusters versus $2 \mathrm{~g} / \mathrm{L}$ in primary clusters. It is well known that post-veraison malate degradation is enhanced by high temperatures [31,32], whereas this effect does not occur for tartaric acid [31,33]. Therefore, GDD/day from veraison onward for forced clusters (9.5-11.5) compared to the heat available for 
primary cluster over the same time span ( 16 GDD/day) likely explain the difference in malic acid retention. While such desirable effect was somewhat expected, it is very meaningful that, in all forced cluster TSS and color from one side and TA from the other side were strongly decoupled; TSS and color responses were primarily controlled by LA/Y ratios and patterns of leaf senescence and function over the season, whereas TA (hence malate) response was mostly temperature driven. It is useless saying that such types of decoupling can turn out very useful in warm environments where maintenance of an adequate acidity level is crucial if sparkling wine types need to be elaborated.

Finally, the final grape composition described for the forced clusters also poses a challenging enological question as high TSS, good color, low $\mathrm{pH}$ and high acidity do seem to co-exist. Here, the matter seems to be redirected to growing conditions and length of the ripening season; pots might have exerted some limitation on the ripening potential whereas having a season providing a slightly longer ripening window could easily lead to a final grape composition of forced clusters that could also be used for a still, aged wine.

Although the technical specifications of the technique will need field growing conditions, it is a reasonable expectation that shoot trimming can be performed using an over-the-row mechanical trimmer. It is also possible that the same machine action might also remove some laterals that have already grown from the basal nodes, in that they facilitate the push of the dormant buds. Then, if mechanization is also a priority for a more sustainable management, the late season crop load can easily be mechanically harvested.

\section{Conclusions}

This is the first contribution to the literature showing that, in Pinot noir, a double-pruning technique was utilized to obtain a second crop in addition to the retained, primary one. This process delayed ripening of both crops, leading to improved fruit quality at harvest. Additionally, this approach did not impact fruitfulness of the basal primary nodes. The application of crop-forcing at the full-flowering or pea-size developmental stage of the primary crop maintained the fruitfulness of the released dormant bud that typically pushed from the apical node of the main shoot trimmed above node six. Overall, F2 (carried out at fruit-set) was preferable to F1 and F3 in terms of milder ripening delay of the primary crop versus the unforced vines, and stronger vegetative growth upon forcing and optimal LA/Y ratios. Forcing achieved $40 \%-50 \%$ additional yield as related to the primary yield. Clusters of forced treatments picked at the very latest date combined high TSS, anthocyanins, TA, malate and low $\mathrm{pH}$ due to either exploitation of a cooler ripening season and/or better leaf and canopy function.

While longer term validation versus field condition and an array of cultivars and environments are certainly needed, these results represent the first proof of concept that double cropping is feasible, and that compositional traits of both crops might also be suitable to encompass different wine styles. A key mechanism that future field studies will have to clarify is the impact of a double cropping on vine vigor and reserve storage. Theoretically, the double cropping might turn out to be useful when vines manifest excessive vigor; whereas under weaker conditions, an excessive source limitation might be expected and will have to be carefully quantified.

Author Contributions: Conceptualization, S.P.; methodology, S.P., T.F., P.S.; investigation, T.F., C.S., N.L.R.; resources, S.P.; data curation, C.S., T.F., S.P., P.S.; writing-original draft preparation, S.P., T.F., P.S.; writing一review and editing, S.T., M.G.; supervision, S.P. All authors have read and agreed to the published version of the manuscript.

Funding: This research received no external funding.

Acknowledgments: The authors want to thank Maria Giulia Parisi, Luca Bricchi and Stefano Santelli for the technical help and Joshua Van der Weide for checking the written English style.

Conflicts of Interest: The authors declare no conflict of interest. 


\section{References}

1. Poni, S.; Gatti, M.; Palliotti, A.; Dai, Z.; Duchêne, E.; Truong, T.-T.; Ferrara, G.; Matarrese, A.M.S.; Gallotta, A.; Bellincontro, A.; et al. Grapevine quality: A multiple choice issue. Sci. Hortic. 2018, 234, 445-462. [CrossRef]

2. O Sadras, V.; Petrie, P. Climate shifts in south-eastern Australia: Early maturity of Chardonnay, Shiraz and Cabernet Sauvignon is associated with early onset rather than faster ripening. Aust. J. Grape Wine Res. 2011, 17, 199-205. [CrossRef]

3. Palliotti, A.; Tombesi, S.; Silvestroni, O.; Lanari, V.; Gatti, M.; Poni, S. Changes in vineyard establishment and canopy management urged by earlier climate-related grape ripening: A review. Sci. Hortic. 2014, 178, $43-54$. [CrossRef]

4. Leeuwen, V.; Irvine, A.D.; Dubernet, M.; Duchene, E.; Gowdy, M.; Marguerit, E.; Pieri, P.; Parker, A.K.; Rességuier, D.; Ollat, N.; et al. An Update on the Impact of Climate Change in Viticulture and Potential Adaptations. Agronomy 2019, 9, 514. [CrossRef]

5. Friend, A.; Trought, M. Delayed winter spur-pruning in New Zealand can alter yield components of Merlot grapevines. Aust. J. Grape Wine Res. 2007, 13, 157-164. [CrossRef]

6. Friend, A.; Trought, M.; Stushnoff, C.; Wells, G. Effect of delaying budburst on shoot development and yield of Vitis vinifera L. Chardonnay 'Mendoza' after a spring freeze event. Aust. J. Grape Wine Res. 2011, 17, 378-382. [CrossRef]

7. Frioni, T.; Tombesi, S.; Silvestroni, O.; Lanari, V.; Bellincontro, A.; Sabbatini, P.; Gatti, M.; Poni, S.; Palliotti, A. Post-budburst spur-pruning reduces yield and delays fruit sugar accumulation in cv. Sangiovese in central Italy. Am. J. Enol. Vitic. 2016, 67, 419-425. [CrossRef]

8. Moran, M.; Sadras, V.; Petrie, P. Late pruning and carry-over effects on phenology, yield components and berry traits in Shiraz. Aust. J. Grape Wine Res. 2017, 23, 390-398. [CrossRef]

9. Palliotti, A.; Frioni, T.; Tombesi, S.; Sabbatini, P.; Cruz-Castillo, J.G.; Lanari, V.; Silvestroni, O.; Gatti, M.; Poni, S. Double-Pruning Grapevines as a Management Tool to Delay Berry Ripening and Control Yield. Am. J. Enol. Vitic. 2017, 68, 412-421. [CrossRef]

10. Petrie, P.; Brooke, S.; Moran, M.; Sadras, V. Pruning after budburst to delay and spread grape maturity. Aust. J. Grape Wine Res. 2017, 23, 378-389. [CrossRef]

11. Gatti, M.; Pirez, F.; Frioni, T.; Squeri, C.; Poni, S. Calibrated, delayed-cane winter pruning controls yield and significantly postpones berry ripening parameters in Vitis vinifera L. cv. Pinot Noir. Aust. J. Grape Wine Res. 2018, 24, 305-316. [CrossRef]

12. Silvestroni, O.; Lanari, V.; Lattanzi, T.; Palliotti, A. Delaying winter pruning, after pre-pruning, alters budburst, leaf area, photosynthesis, yield and berry composition in Sangiovese (Vitis vinifera L.). Aust. J. Grape Wine Res. 2018, 24, 478-486. [CrossRef]

13. Dry, P. How to grow 'cool climate' grapes in hot regions. Austr Grapegrow. Winemak. 1987, 283, $25-26$.

14. Gu, S.; Jacobs, S.D.; McCarthy, B.S.; Gohil, H.L. Forcing vine regrowth and shifting fruit ripening in a warm region to enhance fruit quality in 'Cabernet Sauvignon' grapevine (Vitis vinifera L.). J. Hortic. Sci. Biotechnol. 2012, 87, 287-292. [CrossRef]

15. De Toda, M.F.; García, J.; Balda, P. Preliminary results on forcing vine regrowth to delay ripening to a cooler period. Vitis 2019, 58, 17-22.

16. Martínez-Moreno, A.; Sanz, F.; Yeves, A.; Gil-Muñoz, R.; Martínez, V.; Intrigliolo, D.; Buesa, I. Forcing bud growth by double-pruning as a technique to improve grape composition of Vitis vinifera L. cv. Tempranillo in a semi-arid Mediterranean climate. Sci. Hortic. 2019, 256, 108614. [CrossRef]

17. Lavado, N.; Uriarte, D.; Mancha, L.A.; Moreno, D.; Valdés, E.; Prieto, M.H. Effect of forcing vine regrowth on 'Tempranillo' (Vitis vinifera L.) berry development and quality in Extremadura. Vitis 2019, 58, 135-142.

18. Lorenz, D.; Eichhorn, K.; Bleiholder, H.; Meier, U.; Klose, R.; Weber, É. Growth Stages of the Grapevine: Phenological growth stages of the grapevine (Vitis vinifera L. ssp. vinifera)—Codes and descriptions according to the extended BBCH scalet. Aust. J. Grape Wine Res. 1995, 1, 100-103. [CrossRef]

19. Iland, P.; Dry, P.; Proffitt, T.; Tyerman, S. The Grapevine: From the Science to the Practice of Growing Vines for Wine; Patrick Iland Wine Promotions Pty Ltd.: Adelaide, Australia, 2011; p. 310.

20. May, P.; Antcliff, A.J. The fruitfulness of grape buds. I. Measuring bud fruitfulness on forced single-node cuttings. Ann Amélior. Plantes 1973, 23, 1-12. 
21. Williams, L.E. Bud development and fruitfulness of grapevines. In Raisin Production Manual; Christensen, L.P., Ed.; University of California Division of Agriculture and Natural Resources: Davis, CA, USA, 2000; pp. 24-29.

22. Sánchez, L.A.; Dokoozlian, N.K. Bud microclimate and fruitfulness in Vitis vinifera L. Am. J. Enol. Vitic. 2005, 56, 319-329.

23. Pratt, C. Vegetative Anatomy of Cultivated Grapes-A Review. Am. J. Enol. Vitic. 1974, 25, 131-150.

24. May, P. From bud to berry, with special reference to inflorescence and bunch morphology in Vitis vinifera L. Aust. J. Grape Wine Res. 2000, 6, 82-98. [CrossRef]

25. Or, E.; Vilozny, I.; Fennell, A.; Eyal, Y.; Ogrodovitch, A. Dormancy in grape buds: Isolation and characterization of catalase cDNA and analysis of its expression following chemical induction of bud dormancy release. Plant Sci. 2002, 162, 121-130. [CrossRef]

26. Huglin, P. Biologie et Ecologie de la Vigne; Payot Tech \& Documentation Ed. Lausanne: Paris, France, 1986; p. 382.

27. Bernizzoni, F.; Gatti, M.; Civardi, S.; Poni, S. Long-term performance of Barbera grown under different training systems and within-row vine spacings. Am. J. Enol. Vitic. 2009, 60, 339-348.

28. May, P. Flowering and Fruitset in Grapevines; Lythrum Press: Adelaide, Australia, 2004.

29. Howell, G.S. Sustainable grape productivity and the growth-yield relationship: A review. Am. J. Enol. Vitic. 2011, 52, 165-174.

30. Poni, S.; Giachino, E. Growth, photosynthesis and cropping of potted grapevines (Vitis vinifera L. cv. Cabernet Sauvignon) in relation to shoot trimming. Aust. J. Grape Wine Res. 2000, 6, 216-226. [CrossRef]

31. Buttrose, M.; Hale, C.; Kliewer, W.M. Effect of temperature on the composition of Cabernet Sauvignon berries. Am. J. Enol. Vitic. 1971, 22, 71-75.

32. Ford, C.M. The biochemistry of organic acids in the grape. In The Biochemistry of the Grape Berry; Geros, H., Chaves, M.M., Delrot, S., Eds.; Bentham Science Publishers: Sharjah, United Arab Emirates, 2012; pp. 67-88.

33. Dokoozlian, N.; Kliewer, W. Influence of Light on Grape Berry Growth and Composition Varies during Fruit Development. J. Am. Soc. Hortic. Sci. 1996, 121, 869-874. [CrossRef]

(C) 2020 by the authors. Licensee MDPI, Basel, Switzerland. This article is an open access article distributed under the terms and conditions of the Creative Commons Attribution (CC BY) license (http://creativecommons.org/licenses/by/4.0/). 